\title{
CARACTERIZAÇÃO DE MATERIAIS E DESENVOLVIMENTO DE SIMULAÇÕES DE EFEITOS INDIRETOS DE RAIOS.
}

\section{Renan H. M. Callegari, José Pissolato Filho.}

\section{Resumo}

Este projeto de iniciação científica (IC) está ligado a um projeto desenvolvido pela UNICAMP em parceria com a empresa EMBRAER. A parte do projeto pela qual a UNICAMP e a iniciação cientifica estão responsáveis está voltada a desenvolver um trabalho de medição e caracterização de materiais. Além disso, o projeto dará suporte acadêmico para áreas relacionadas a simulação computacionais para estimativa de funções de transferência de acoplamento eletromagnético das instalações elétricas dos sistemas embarcados em aeronaves civis. Será possível, após o estudo, ter maior entendimento a respeito do fenômeno e, assim, buscar soluções aplicáveis aos sistemas reais utilizado em aeronaves civis.

\section{Palavras-chave:}

Descargas Atmosféricas , Aeronaves, Simulações.

\section{Introdução}

Constantemente sujeitas as regiões de tempestade, as aeronaves são frequentemente expostas a estas descargas durante uma viagem, tendo em vista, dessa forma, a segurança do sistema elétrico embarcado que compõe a aeronave, se faz necessário o estudo do impacto que uma carga elétrica de alta intensidade, proveniente de uma descarga atmosférica, que tem sobre o mesmo. O projeto visa desenvolver um trabalho de medição e caracterização de materiais por via de simulações computacionais. A representação de produtos "reais", o qual demonstra a validade da abordagem de engenharia, reforça a "capacidade industrial" da tecnologia de computação eletromagnética.

\section{Resultados e Discussão}

Para o estudo do eletromagnetismo é preciso abordar as equações que compõe a modelagem deste tipo de fenômeno. As equações de Maxwell que descrevem a teoria eletromagnética, estas são:

$$
\begin{aligned}
& \nabla \times E=-\mu_{0} \frac{\partial H}{\partial t} \\
& \nabla \times H=\varepsilon_{0} \frac{\partial E}{\partial t}+J \\
& \nabla . E=\frac{1}{\varepsilon_{0}} \sigma \\
& \nabla . E=0
\end{aligned}
$$

Onde $\mu_{0}$ e $\varepsilon_{0}$ são a permeabilidade magnética e a permissividade elétrica do meio, $E$ é o campo elétrico e $H$ o campo magnético e $l$ representa a densidade de corrente e $\sigma$ a densidade de carga.

No meio natural as ondas eletromagnéticas geradas se propagam até atingir um segundo corpo, onde neste é induzida uma corrente e este corpo por sua vez passa gerar um segundo campo eletromagnético, isto é chamado de espalhamento eletromagnético, de forma geral existem duas que descrevem bem o fenômeno.

$$
\begin{aligned}
& \nabla^{2} E+K_{0}{ }^{2} E=0 \\
& \nabla^{2} H+K_{0}{ }^{2} H=0
\end{aligned}
$$

Onde $K_{0}=\omega \sqrt{\mu_{0} \varepsilon_{0}}$ A equação 5 é de onda vetorial do campo elétrico enquanto que a 6 é a equação de onda do campo magnético.

Abaixo, na figura 1, pode-se observar as linhas do campo magnético após a simulação.

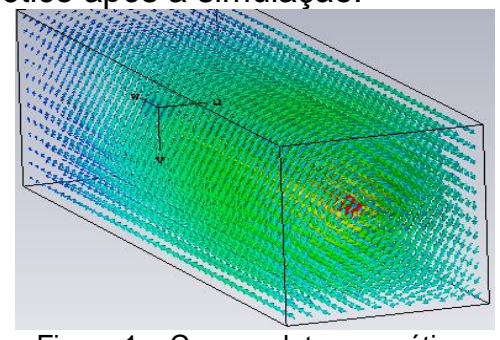

Figura 1 - Campo eletromagnético.

Semelhantemente a uma situação real, as linhas de campo são densas e circundam o fio condutor

Outro resultado coletado foi o campo elétrico ao redor do fio, na figura 2 abaixo é possivel ver 0 comportamento do mesmo após a aplicação do sinal.

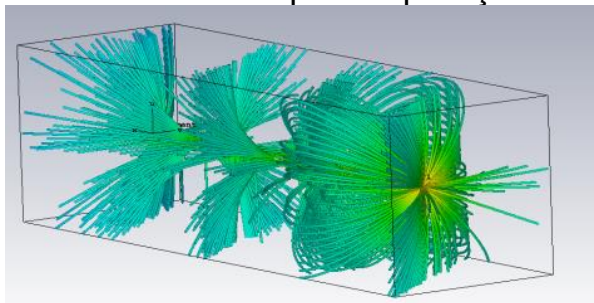

Figura 2 - Campo elétrico

Assim como no caso do campo magnético, a intensidade do campo elétrico pode variar. Futuramente serão executadas dimulações com elementos de maior complexidade para assim análisar a interfereência elétromagnética.

\section{Conclusões}

Até o momento o projeto tem concluiu com êxito suas etapas iniciais, espera-se que através destas etapas 0 projeto possa dar prosseguimento as simulações, definido um plano de ensaio e coletando resultados concretos. 